\title{
Epigenetics of Cardiovascular Disease: A New 'Beat' in Coronary Artery Disease
}

\author{
Paul J. Turgeon ${ }^{a, c}$ Aravin N. Sukumar ${ }^{b, c}$ Philip A. Marsden ${ }^{a-c}$ \\ ${ }^{a}$ Department of Laboratory Medicine and Pathobiology, ${ }^{b}$ Institute of Medical Science, and \\ 'Department of Medicine, Keenan Research Centre for Biomedical Science and Li Ka Shing \\ Knowledge Institute, St. Michael's Hospital, University of Toronto, Toronto, Ont., Canada
}

Key Words

ANRIL · Coronary artery disease · DNA methylation · Epigenetics · Endothelial cells ·

Endothelial nitric oxide synthase $\cdot$ Histone post-translational modifications and density ·

Long non-coding ribonucleic acid

\section{Abstract}

Genome-wide association studies have become a powerful tool in the identification of disease-associated variants. Unfortunately, many of these studies have found that the estimated variability in cardiovascular disease (CVD) risk cannot be fully explained by traditional paradigms of genetic variation in protein-coding genes. Moreover, traditional views do not sufficiently explain the well-known link between CVD and environmental influence. We posit that epigenetics, defined as chromatin-based mechanisms important in the regulation of gene expression that do not involve changes in the DNA sequence per se, represents the missing link. The nuclear-based mechanisms that contribute to epigenetic gene regulation can be broadly separated into three unique but highly interrelated processes, namely DNA methylation and hydroxymethylation, histone density and post-translational modifications, and ribonucleic acid-based mechanisms. Together, they complement the cis/trans perspective on transcriptional control paradigms in blood vessels. Moreover, epigenetics provides a molecular basis for understanding how the environment influences the genome to modify CVD risk over the lifetime of a cell and its offspring. This review is an introduction to epigenetic function and CVD, with a focus on endothelial cell biology. Additionally, we highlight emerging concepts on epigenetic gene regulation that are highly relevant to atherosclerosis and coronary artery disease. 
Turgeon et al.: Epigenetics of Cardiovascular Disease: A New 'Beat' in Coronary Artery Disease

\section{Introduction}

According to a report by the American Health Association from 2009, 1 in 3 deaths in the USA was attributed to cardiovascular disease (CVD), which translates to 1 death every $40 \mathrm{~s}$ [1]. CVD as a whole is estimated to have cost the USA 312.4 billion USD that year, an amount that exceeded the costs of any other disease group. Moreover, this burden is expected to worsen due to an aging population and a shift in environmental risk factors in developing and third world populations toward diets with higher sodium and fat content. Unique regions of the human vasculature affected include the coronary arteries, carotid arteries, and the peripheral arterial network [2]. In particular, coronary artery disease (CAD), which disrupts the oxygen-rich blood flow to the heart, is the most common type of heart disease and the most common cause of death in both men and women in the USA. Based on the 2009 statistics from the USA, CAD alone accounts for approximately 1 out of every 6 deaths, which projects to an estimated 386,000 deaths due to CAD [1].

CAD manifests from the progressive narrowing and either acute or chronic occlusion of blood vessels due to the gradual process of plaque formation, a process known as atherosclerosis [2]. As a result, stenosis of the vessel or thrombosis can occur and lead to angina pectoris and/or myocardial infarction (MI). Atherosclerosis is a complex inflammatory disease with well-defined genetic determinants as well as environmental risk factors supported by discordance between monozygotic (MZ) twins, sexual dimorphism, parent-oforigin-dependent clinical differences, and a relatively late age at the onset of disease manifestation [3]. The environmental factors likely influence the progressive stages of atherosclerotic plaque formation through their interaction with the endothelium, the innermost lining of the vasculature system, causing endothelial dysfunction. Endothelial cell (EC) 'dysfunction' represents a net liability to the host through the disruption of its homeostatic functions including vasomotor tone, leukocyte trafficking, and hemostasis [4]. Typically, endothelial dysfunction and lesion initiation is thought to be triggered by risk factors such as elevated blood pressure, diabetes, dyslipidemia, and smoking. Although these risk factors affect the circulatory system in a systemic manner, the development of lesions displays a focal distribution [5]. This pattern is not arbitrary, as numerous studies have identified a role for hemodynamics in promoting atherosclerosis, particularly in CAD patients [6]. Investigating both the genetic and environmental basis of CAD will allow us to design new and more effective therapeutic strategies.

\section{Heritability versus Environment: Implications for Future Generations}

Our knowledge of CAD has evolved in parallel with advances in our understanding of atherosclerosis as a whole. Atherosclerotic disease of the carotid and peripheral vasculature system share common determinants. Traditional risk factors that increase the risk of CAD are well established and include hypertension, dyslipidemia, and diabetes. However, the molecular mechanisms that promote CAD in individuals affected by these environmental factors are still unclear. Surprisingly, these environmental changes can have transgenerational effects. Furthermore, numerous studies have revealed a genetic predisposition for CAD, in particular twin studies that suggest a heritable component for the disease [7]. However, studies have revealed that approximately 8-13\% of the estimated CAD heritability is attributed to genetic variation alone [8]. We argue that the impact of gene-environment interactions have been underestimated and that the heritable component of CAD is not fully defined, but these challenges can potentially be resolved by applying the epigenetic theory of complex, non-Mendelian diseases. 
The implementation of classical twin studies has proved to be a valuable tool in assessing the genetic contribution in many diseases, including CAD [7, 9]. The fundamental principle of these studies is that MZ twins are nearly genetically identical, whereas dizygotic (DZ) twins only share approximately $50 \%$ of their genome. Therefore, if the concordance rate for a trait/ disease is greater in MZ twins compared to DZ twins, a genetic component can be hypothesized for the disease phenotype. A study on 10,502 Swedish twin pairs from 1994 revealed a genetic component in CAD as the mortality of a co-twin led to the doubling of the relative hazard for death by CAD in MZ twins relative to DZ twins [7]. Similarly, a separate study on Danish twins also observed a strong genetic influence on mortality caused by CAD [10]. With respect to CAD, heritability of frailty (or liability to death) was found to be 0.55 and 0.53 for males and females, respectively. Although a genetic component is apparent, there was considerable discordance among MZ twins for death due to CAD. How can this discordance for CAD within MZ twin pairs be explained? Here, we argue that gene-environment interactions are also important. Surprisingly, our understanding of the mechanistic links between environmental risk factors and CAD is poorly understood [9].

The application of genome-wide association studies (GWAS) has further expanded our knowledge of the role of genetics in the development of CAD. The ultimate purpose of these studies is to evaluate the association between genomic and phenotypic variation in a disease population by identifying single-nucleotide polymorphisms (SNPs) or single-nucleotide variants that are correlated with the disease [11]. Although GWAS are powerful tools for exploring the genetic architecture of non-Mendelian diseases in an unbiased manner, they do have some limitations. They are dependent on the 'common disease, common variant' hypothesis, which postulates that common diseases are attributable to common risk variants found within at least $1-5 \%$ of the total population [11]. However, for most common human diseases or complex traits, susceptibility risk variants only account for a modest increase in risk (1-1.5 fold) and explain only a small proportion of the estimated variability. For example, Marenberg et al. [7] demonstrated that $30-60 \%$ of all interindividual variability in the CAD risk is attributable to genetic factors. What does this 'missing heritability' in GWAS of complex diseases such as CAD account for? We argue that the epigenetic theory provides an alternative paradigm that accounts for, at least in part, the missing heritability of complex diseases. Interestingly, using a method designed to identify genomic susceptibility loci has instead identified epigenetic effectors as the major determinants of CAD liability. In 2007, multiple research groups identified a genomic susceptibility locus for CVD heritability within the intergenic non-coding region of chromosome 9p21 (Ch9p21) [reviewed in 12,13]. This locus contains a long non-coding ribonucleic acid (lncRNA), referred to as antisense non-coding RNA in the INK4 locus (ANRIL; further discussed below), and is the most replicated marker of CAD and MI, independent from most traditional risk factors, and its expression is correlated with atherosclerotic lesions [14]. The finding that a long non-coding RNA may be relevant to CAD pathogenesis was surprising.

The evolving study of transgenerational epigenetics addresses the capacity of an offspring's epigenetic profile to be influenced by environmental factors from preceding generations (fig. 1) [15]. Epigenetics is defined as chromatin-based mechanisms important in the regulation of gene expression that do not involve changes in the DNA sequence per se [3]. Epigenetic processes are known to be triggered by changes in the environment, allowing cells to rapidly adapt to their dynamic surroundings. These modifications can persist in subsequent generations and contribute to disease risk in individuals [15]. Additionally, gene imprinting refers to chromatin-based mechanisms that regulate the monoallelic expression of either the paternal or maternal gene in a parent-of-origin fashion. There is evidence that transgenerational diseases can disrupt genomic imprinting and subsequently enhance the risk for disease in future generations. The Dutch Hunger Winter Famine of 1944-1945 is a 


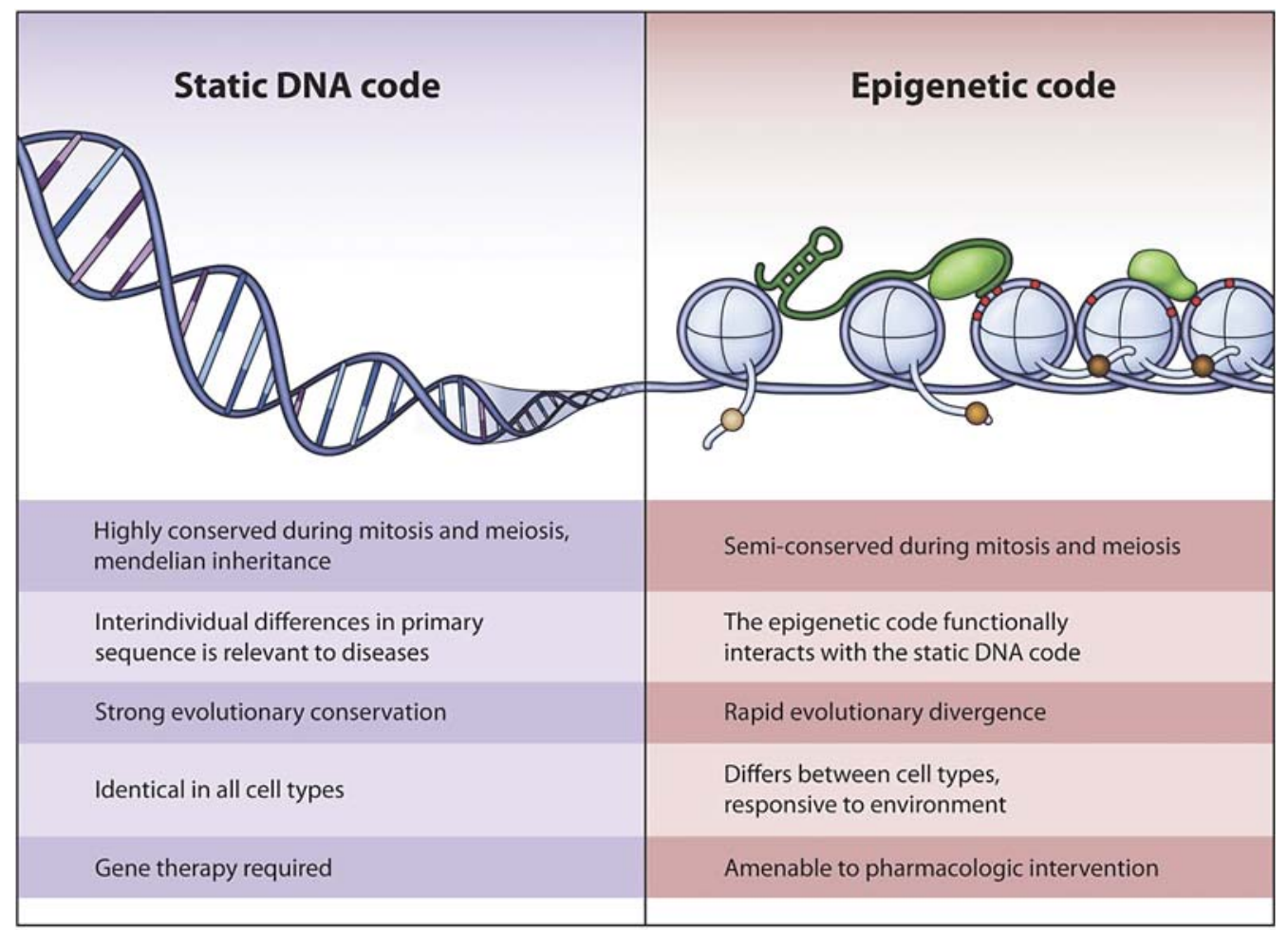

Fig. 1. Comparison of key facets of the genetic and epigenetic codes. Within a multicellular organism, all cells show an identical genetic code, the static A-T-C-G bases, which are conserved with cellular replication in mitosis and meiosis. This has been conserved throughout evolution from single cells to multicellular organisms. Therapy for defects in the static DNA code is complicated due to the complexity of gene therapy in multicellular organisms. The epigenetic code is semi-conserved in meiosis and mitosis and shows rapid divergence across species. Notably, it is different in all cells of multicellular organisms and responsive to the environment, making it a candidate target for pharmacologic intervention.

prominent example of the influence of transgenerational epigenetics and gene imprinting on disease risk inheritance [16]. In the offspring of mothers who were malnourished during this period, whole blood extracts were found to display reduced DNA methylation in the maternal insulin-like growth factor 2 gene. Interestingly, the offspring of these affected individuals developed CAD earlier than healthy subjects [17]. This evidence suggests that environmental factors from previous generations can confer susceptibility for diseases in the present day, perhaps through epigenetic mechanisms that are passed on through meiosis.

In conclusion, these three perspectives on CAD - discordance of MZ twins for CAD, missing heritability in GWAS, and transgenerational effects of the environment - demonstrate the limitations of using traditional disease models to understand the risk factors for CAD.

\section{Gene Expression in Vascular Endothelium: The influence of Environment, Specifically Hemodynamics, on EC Phenotype}

Epigenetics is an alternative perspective that may enable us to fully understand the genetic and environmental basis of CAD. Our present environment is abundant in risk factors that influence vascular health and disease and can initiate CVD in general and CAD specifi- 
Turgeon et al.: Epigenetics of Cardiovascular Disease: A New 'Beat' in Coronary Artery Disease

cally. Within the context of CAD, the endothelium is a key intermediary between environmental stimuli and the progression of atherosclerosis. Due to their location along the blood vessel wall, ECs are constantly exposed to circulating humoral factors, blood cellular constituents, other vessel wall types, and the physical forces of circulation [18]. ECs are able to sense these distinct stimuli rapidly and to respond accordingly to maintain vascular homeostasis and hemostasis. A good example is the ability of ECs to release vasoconstrictors and vasodilators that control local vasomotor tone [19]. The development of atherosclerosis typically begins with the onset of inflammation due to a range of risk factors such as elevated levels of low-density lipoprotein cholesterol, high glucose, or smoking [5]. Chronic exposure to these environmental factors can result in 'endothelial dysfunction', which is primarily characterized by a reduction in endothelial nitric oxide synthase (eNOS; NOS3) expression (further discussed below) and the bioavailability of NO. Given NO's anti-inflammatory and antiatherosclerotic properties, its reduction can exacerbate the inflammatory response, which sets the stage for atherosclerosis [5]. Furthermore, endothelial dysfunction is associated with changes in other important genes, which contribute to a pro-atherosclerotic phenotype. For example, there is downregulation of several genes associated with 'atheroprotection', including Krüppel-like factor 2, as well as upregulation of genes that are pro-inflammatory, such as endothelin-1 [20, 21].

Although common risk factors for CAD, such as diabetes or smoking, affect the entire vasculature, there is compelling evidence in human and animal models that atherosclerotic lesions display a site-specific distribution [5]. This unexpected observation appears to be due to changes in the physical forces of the blood circulation or 'hemodynamics'. The endothelium is exposed to different forms of hemodynamic forces, but most attention has been on the influence of shear rate and shear stress on EC biology (fig. 2). The movement of blood can be modeled as a series of concentric layers called laminae. Shear rate (expressed as s ${ }^{-1}$ ) is defined as the rate at which adjacent layers of fluid move with respect to each other [22]. On the other hand, shear stress (expressed as dynes $/ \mathrm{cm}^{2}$ ) is the tangential frictional force per area generated at the surface of the endothelium by the blood flow. With the assumption that blood is a Newtonian fluid, shear stress is dependent on the level of shear rate and viscosity of the fluid [21]. The relationship between hemodynamics and site propensity of atherosclerosis is centered on two unique patterns of arterial blood flow, atheroprotective and atheroprone flow, both of which have been modeled in vitro [20,23]. Atheroprotective flow typically occurs in straight segments of the arterial network (e.g. descending thoracic aorta), where blood flow is laminar and associated with physiological levels of shear rate and shear stress. In contrast, atheroprone flow is characterized by turbulent flow that occurs at geometrical irregularities such as bifurcations or curvatures (e.g. lesser curvature of the aortic arch), resulting in flow reversal and low levels of shear rate/stress. Importantly, human coronary arteries are known to experience atheroprone flow [23]. These distinct types of flow have a significant impact on EC gene expression and phenotype, and most importantly, inflammation. In response to low shear stress and/or oscillatory flow, ECs exhibit a dysfunction phenotype [20]. There is a lack of understanding in how ECs respond and adapt to changes in environmental conditions, in particular the changes in blood flow, and we believe that the remarkable plasticity of ECs can be attributed to epigenetic mechanisms.

\section{Epigenetics: Basic Mechanisms and the Endothelium}

The haploid human genome is made up of approximately 3.3 billion DNA base pairs. Size variation reflects interindividual differences in copy number variation and sex-specific differences (i.e. X- vs. Y-chromosome length). Given the size of an individual base pair, the DNA 
Turgeon et al.: Epigenetics of Cardiovascular Disease: A New 'Beat' in Coronary Artery Disease

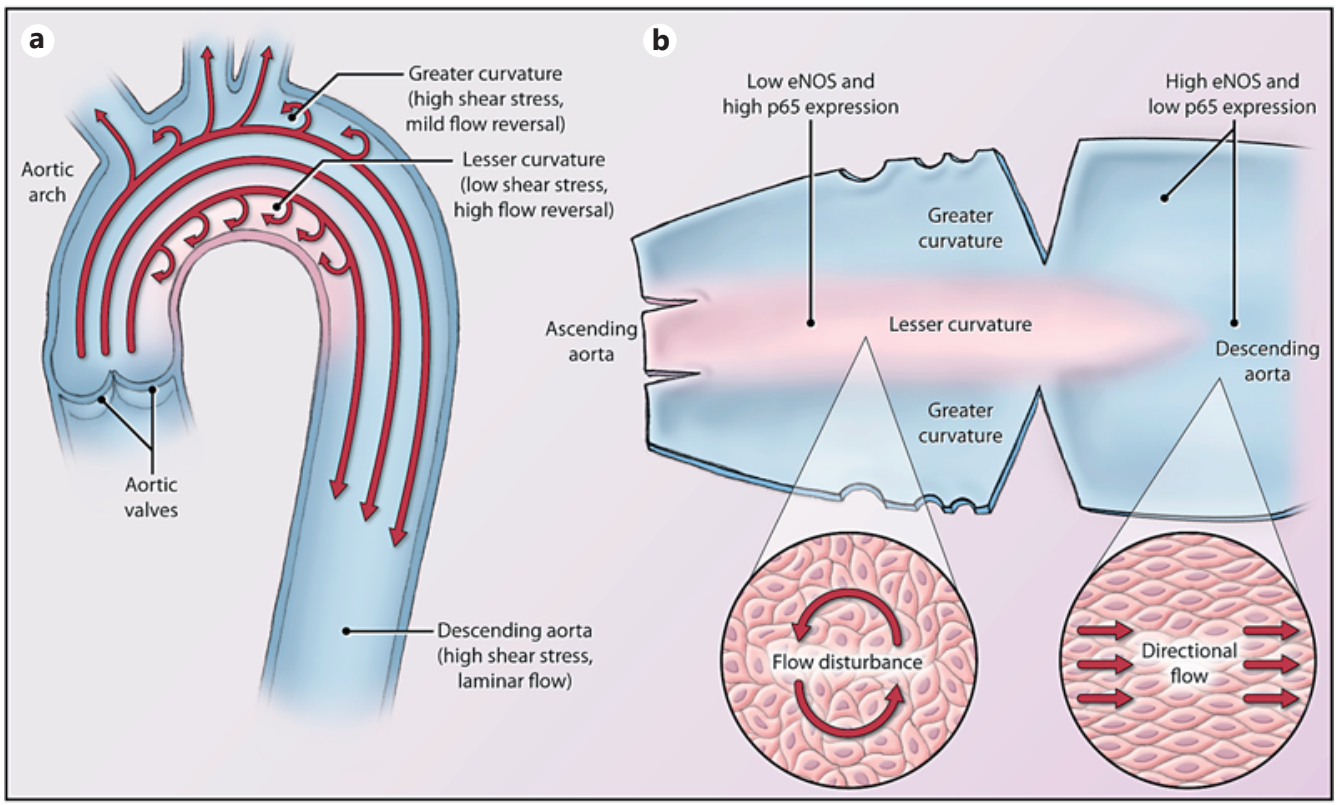

Fig. 2. Flow and endothelial phenotypes in the aortic arch. a Flow patterns of the aortic arch display both laminar flow in the greater curvature and disturbed flow in the lesser curvature. b Dissection of the aortic arch reveals interesting phenotypic changes in ECs. ECs of the greater curvature experience laminar flow, exhibit eNOS expression and decreased p65 expression, an inflammatory mediator in ECs, and are less prone to atherosclerosis. These cells show a directional cell shape, which corresponds with directional flow. ECs of the lesser curvature of the aortic arch are prone to atherosclerosis, decreased eNOS expression, and p65 enrichment. These ECs also experience disturbed flow and exhibit a disorganized pattern.

strand from a single cell would span approximately $2 \mathrm{~m}$ in length. The compaction of genomic DNA into the eukaryotic cell nucleus is a marvelous example of the packing of DNA into a DNAprotein complex referred to as chromatin. The human nucleosome, $146 \mathrm{bp}$ of DNA wrapped around an octamer of core histone proteins, is composed of two molecules each of H2A, H2B, $\mathrm{H} 3$, and H4. Adjacent nucleosomes are linked by short stretches of linker DNA and the less conserved histone $\mathrm{H} 1$. The epigenetic theory constitutes the molecular effectors that regulate the structure and accessibility of chromatin without changing the underlying A-C-G-T genetic code per se. They constitute a highly integrated and evolutionarily conserved system for regulated gene expression (fig. 3 ) and will be individually elaborated in the following sections.

\section{DNA Methylation/Hydroxymethylation}

DNA methylation refers to the covalent modification of the 5-position of cytosine to generate 5-methylcytosine, commonly referred to as the 'fifth base of DNA' [24]. The understanding of the establishment and function of DNA methylation has increased since its initial discovery in mammals by Hotchkiss in 1948 [25]. Early work revealed that 5-methylcytosine continues to base pair with guanine, is passed on semi-conservatively with DNA replication and is highly restricted to $\mathrm{CpG}$ dinucleotides in mammals. Although evolution of the mammalian genome has left it relatively $\mathrm{CpG}$ depleted due to spontaneous deamination of the methylated cytosine to thymine, the genome does contain regions that are not $\mathrm{CpG}$ depleted [26]. These are referred to as $\mathrm{CpG}$ islands. DNA methylation is traditionally viewed as a repressive mark associated with inhibition of transcriptional initiation when found adjacent to promoters. It is therefore important in silencing many developmental elements involved in genomic 


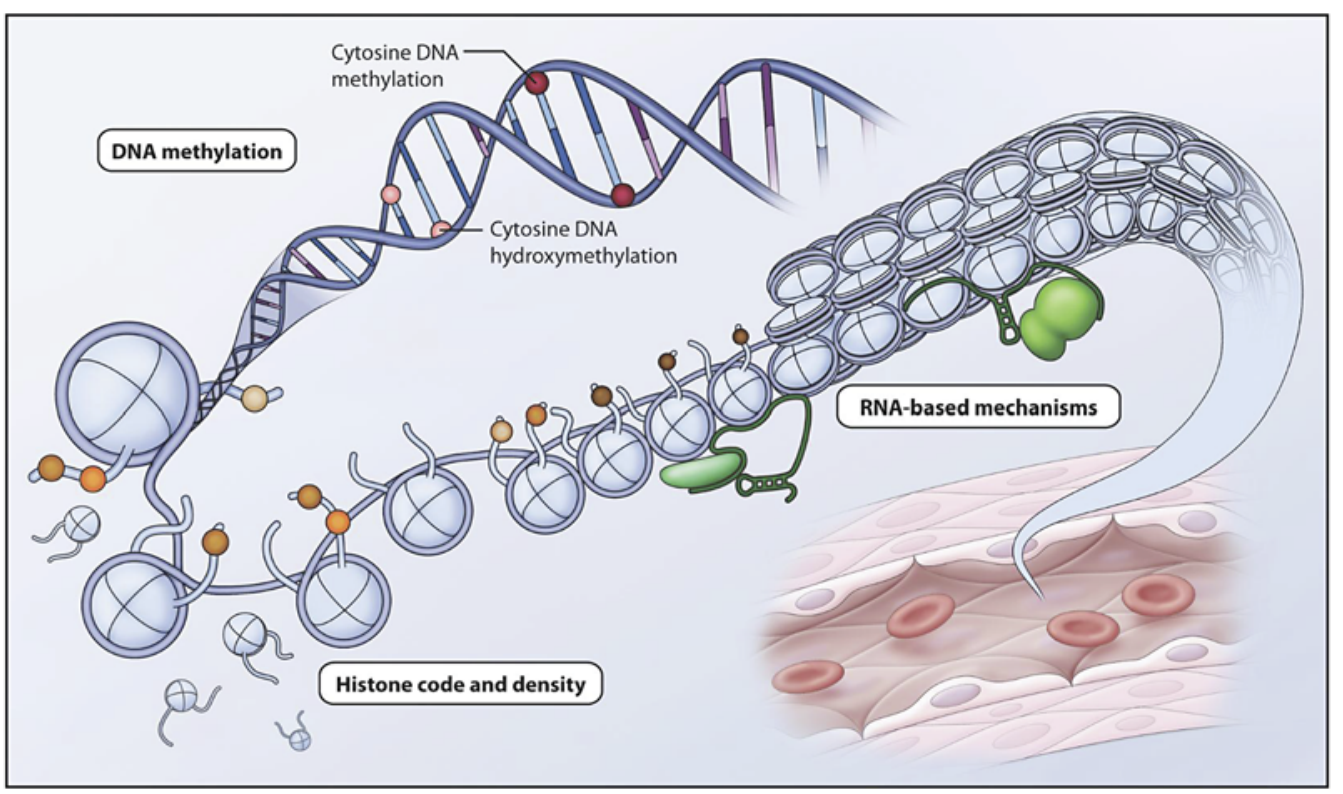

Fig. 3. Epigenetics can be separated into three distinct but highly interrelated processes: DNA methylation, histone density and post-translational modifications, and RNA-based mechanisms. DNA methylation refers to the addition of a methyl group to the 5-position of cytosine and is a repressive mark, which occurs symmetrically almost exclusively in the context of $\mathrm{CpG}$ dinucleotides in mammals. 5-hydroxymethylation also occurs at $\mathrm{CpG}$ dinucleotides and is thought to act as an intermediate for active demethylation. Histone density and post-translational modifications refer to the presence of histones and N-terminal histone tail posttranslational modifications, respectively. These changes alter histone protein-DNA interactions and change the chromatin structure to affect the accessibility of transcription factors modulating gene transcription. RNA-based mechanisms including lncRNAs interact with chromatin and chromatin-modifying complexes in cis or trans to modulate gene expression.

imprinting, $\mathrm{X}$ chromosome inactivation, mammalian embryogenesis and cellular differentiation. It also serves as a protective mechanism to silence repetitive DNA elements, which make up $25-40 \%$ of the mammalian genomes, depending on how one defines 'repetitive'. In general, DNA methylation is a relatively stable covalent DNA modification [24].

In mammals, the DNA methyltransferase (DNMT) family of enzymes catalyzes the addition of a methyl group from S-adenosyl methionine to the 5-position of cytosine. The ability of 5-methylcytosine to be propagated throughout mitotic divisions is due to the maintenance methyltransferase DNMT1 [27]. DNMT1 shows preferentially binding to hemimethylated DNA, typically at the DNA replication fork, and methylates the complementary cytosine. Notably, DNMT1 has been shown to be relatively inefficient at maintaining the methylation of $\mathrm{CpG}$, especially in $\mathrm{CpG}$-dense regions. In order to establish new methylation profiles after replication, the other two family members, DNMT3A and DNMT3B, are recruited to de novo methylate CpGs. They are thought to exert their main function in establishing methylation patterns on unmethylated DNA during embryogenesis and early development [27]. Although a stable mark, removal of DNA methyl groups can occur, especially during development. Passive DNA demethylation can occur in primordial germ cells and preimplantation embryos, where a reduction in DNMT activity may be observed [28]. An area of more active research is on the site-specific removal of cytosine methylation termed active DNA demethylation. This has been noted when DNA methylation levels change quickly, sometimes within hours. These are DNA replication-independent cellular responses [29]. Active DNA methylation has been 
Turgeon et al.: Epigenetics of Cardiovascular Disease: A New 'Beat' in Coronary Artery Disease

proposed to occur through several pathways, but the most exciting is the recent discovery of the oxidative formation of 5-hydroxymethylcytosine, now known as the 'sixth base of DNA' [30]. The ten-eleven translocation (TET) enzyme family (TET1, TET2 and TET3) act on 5 -methylcytosine to form 5-hydroxymethylation with the subsequent oxidative products 5 -formylcytosine or 5-carboxycytosine being produced [31]. The TET family may work in conjunction with the family of base excision repair glycosylases to regenerate the initial cytosine residue [32]. The function of 5-hydroxymethylcytosine is currently under active study as it was initially thought to be an intermediate in demethylation. However, accumulation in various cell types and its specific recognition by protein complexes may indicate that it also serves a purpose in gene regulation [33].

How does DNA methylation affect gene expression? In general, it is a repressive transcriptional mark. DNA methylation participates in gene repression currently via three distinct mechanisms. First, the presence of the methyl group is thought to directly inhibit DNA binding of some transcription factors such as CTCF, c-Myc, and HIF-1 $\alpha$ [24]. Although seemingly important, few transcription factors have been identified to be affected by DNA methylation. Therefore, this remains an area for future focus. Second, the methyl group can also influence other aspects of epigenetic pathways, namely histone modifications. Recent evidence suggests that DNA methylation inhibits the formation of the activating histone 3 lysine 4 (H3K4) diand trimethyl marks. Last, methyl-binding proteins can bind specifically to methylated CpGs. The recruitment of these proteins is directly mediated by the presence of DNA methylation. Although the mechanism of repression is not fully understood, the members of this family (MBD1, MBD2, MBD3, MeCP2 and Kaiso) are thought to bind repressor proteins and histone deacetylases (HDACs), which mediate inactive chromatin signatures [24, 34]. Methylation is a stable repressive mark and shows semi-conservation with DNA replication, which is important for disease heritability in both the parent and offspring.

\section{Histone Post-Translational Modifications}

The second layer of epigenetic gene regulation resides in the histone proteins around which the DNA double helix is wound. These evolutionarily conserved proteins are comprised of a globular domain and histone tails. In particular, the amino termini histone tails provide a robust platform for a myriad of post-translational modifications that can inform gene expression [35]. To date, more than one hundred distinct modification sites have been characterized [36]. Examples of well-studied histone post-translational modifications include lysine acetylation and lysine methylation, among others (table 1) [35]. Many of these marks are mutually exclusive for any given histone amino acid residue. For example, histone 3 lysine 9 (H3K9) can either be acetylated or methylated, but not both.

Histone post-translational modifications are postulated to regulate gene expression through two broad mechanisms. First, histone post-translational modifications can alter the physical structure of chromatin and its accessibility to DNA-binding proteins such as transcriptional regulators [37]. For example, the higher-order compaction of chromatin is prevented by histone lysine acetylation, whereby acetyl groups neutralize the basic charge of lysine residues, making chromatin more open and accessible to DNA-binding proteins [37]. More important than the direct physical effect on the structure of chromatin, perhaps, is the regulatory information contained within the specific combinations of histone marks. The 'histone code hypothesis' provides the mechanistic concept that a given combination of modifications is 'read' by a combination-specific protein or protein complex to effectuate a specific gene expression outcome [38]. Given the myriad of histone modifications, there are many permutations. Therefore, deciphering the histone code remains a daunting, yet top priority for the epigenetics research community. 
Table 1. Well-studied epigenetic modifications and their effect on gene transcription

\begin{tabular}{ll}
\hline Mechanism & Transcriptional effect \\
\hline DNA modifications & \\
Methylation (CpG dinucleotides) & $\downarrow$ \\
Hydroxymethylation (CpG dinucleotides) & $?$ \\
\hline Histone post-translational modifications & \\
Histone H3 & $\uparrow$ \\
$\quad$ Acetylation (K9, K14) & \\
Methylation & $\uparrow$ \\
$\quad$ K4 & $\downarrow$ \\
$\quad$ K9 & $\downarrow$ \\
$\quad$ K27 & $\uparrow$ \\
$\quad$ K36 & $\uparrow / \downarrow$ \\
Phosphorylation (S10) & $\uparrow$ \\
Histone H4 & $\downarrow$ \\
Acetylation (K5, K8, K12, K16) & $\downarrow$ \\
Methylation (K20) & \\
\hline IncRNA mechanisms & \\
Repressive lncRNAs, & $\downarrow$ \\
e.g. XIST, ANRIL, HOTAIR & \\
Activating lncRNAs, & \\
e.g. HOTTIP & \\
\hline K = Lysine; S = serine. &
\end{tabular}

A series of histone code 'readers', 'writers' and 'erasers' are known [35]. Each modification is catalyzed by an increasingly well-characterized group of 'writers' that can then be interpreted by a distinct group of 'readers' $[3,35]$. In mammalian cells, lysine acetylation is catalyzed by three families of histone acetyltransferases (HATs). Indeed, the demonstration that classical transcriptional coactivators possess intrinsic HAT activity helped to establish histone lysine acetylation as a permissive, epigenetic mark strongly correlated with transcriptional activation [35]. The removal of histone lysine acetylation is accomplished by four families of histone deacetylases (HDAC classes I-IV) or 'erasers'. Experimentally, these families of HDACs are further categorized by their sensitivity to inhibition by the pharmacological agent trichostatin A (TSA). Class I and II HDACs are TSA-sensitive, while class III and IV HDACs are TSA-insensitive. Importantly, HDAC inhibitors have found early clinical utility in the treatment of various cancers, neurodegenerative disease and inflammation [39]. Interestingly, HATs and HDACs demonstrate poor specificity for individual lysine residues and are recruited to target promoters in large, multiprotein complexes through a group of acetyllysine 'readers' that contain a bromodomain [35].

Recent studies on histone lysine methylation underscore the tremendous complexity of epigenetic gene regulation. Unlike histone lysine acetylation, the downstream effects of lysine methylation on gene expression are residue-specific and context-dependent [3, 35, 37]. For example, H3K4 is strongly associated with transcriptional activation, while H3K9 is a classical stable repressive mark associated with heterochromatin formation and transcriptional silencing. Once again, these epigenetic modifications are controlled by distinct groups of 'readers', 'writers' and 'erasers'. Lysine methylation biology is even more finessed. An individual histone lysine residue can be mono-, di-, or trimethylated with profoundly distinct effects on mammalian gene expression. The functional relevance of these nuanced modifications is supported by their differential localization in the genome; for example, it has been 


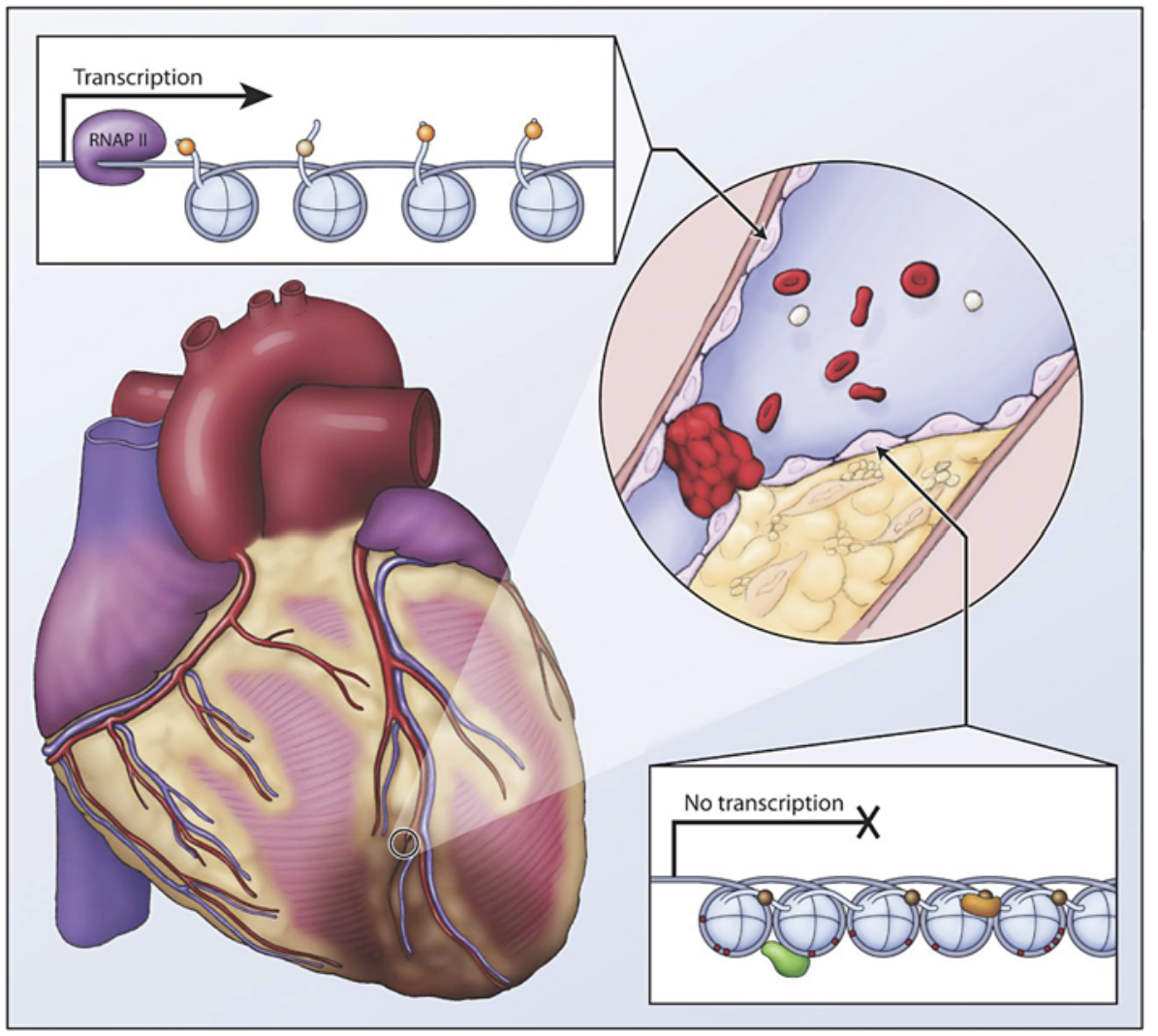

Fig. 4. Large vessel occlusion is a major mechanism of coronary artery disease. Proper gene expression in ECs in healthy vasculature maintains an antithrombotic and antiatherogenic cellular phenotype. Epigenetics may play a role, as chromatin configuration, mediated by environmental influences, can alter the expression of key genes in ECs. An open chromatin configuration would allow transcription of atheroprotective genes such as eNOS in healthy endothelium. In contrast, a dysfunctional endothelium could be characterized by a closed chromatin configuration with a repressive epigenetic profile.

suggested that H3K4 monomethylation preferentially localizes to enhancers and H3K4 trimethylation to active promoters [3, 40].

In addition to the considerable complexity of histone post-translational modifications, important roles for nucleosome density, ATP-dependent chromatin remodeling, and the regulated, replication-independent incorporation of histone variants in the control of mammalian gene expression have been noted $[40,41]$. These additional layers of epigenetic control provide further complexity, sophisticating the highly responsive system superimposed on the static genetic code. Altogether, tremendous strides have been made in understanding the impact of specific histone post-translational and density modifications in the control of mammalian gene expression.

\section{Epigenetic Model: eNOS}

Given the role of EC dysfunction in the initiation, progression and clinical phenotype of atherosclerosis, investigating how gene expression is regulated in these cells and how these processes are perturbed in disease will provide newer insight into the pathogenesis of CAD. A prominent feature of endothelial dysfunction is reduced eNOS expression in the neointimal coverings of advanced atheromatous plaques (fig. 4) [5, 42]. Numerous risk factors contribute 
Turgeon et al.: Epigenetics of Cardiovascular Disease: A New 'Beat' in Coronary Artery Disease

to EC dysfunction through changes in eNOS [5, 42-44]. Mechanistically, important transcriptional and post-transcriptional mechanisms for the control of eNOS mRNA levels have been identified [41, 45-47]. Although a critical biological process due to blood flow, hemodynamic forces at characteristic regions within the vasculature such as arterial curvatures and bifurcations also lead to differential expression of eNOS [5]. A decrease in eNOS activity and an increase in priming of the NF- $\kappa \mathrm{B}$ signal transduction cascade exist in mouse aortas at regions predisposed to atherosclerosis $[5,43]$.

After the cloning of the eNOS gene, the promoter was characterized and examined for mechanisms of EC-restricted expression [48-50]. The initial discovery of the role of epigenetics in eNOS gene expression came from the use of episomal eNOS promoter-reporter constructs. Interestingly, in vitro, all cell types examined were able to express the construct, although the native eNOS gene was EC restricted [47]. This contrasted with stably integrated eNOS promoter-reporter transgenic mice that demonstrated a similar expression pattern to eNOS in humans [51]. Direct evidence of eNOS epigenetic regulation was observed in that the eNOS promoter showed DNA hypomethylation in ECs but dense methylation in nonexpressing cells such as vascular smooth muscle cells [47]. This DNA methylation was shown to be functionally relevant. This idea of endothelial-enriched expression due to differential DNA methylation has recently been expanded to encompass several other important EC-enriched genes such as CD31, vWF, and ICAM-2 [52]. Further examination of the eNOS promoter revealed the presence of activating histone marks such as acetyl $\mathrm{H} 3$ and $\mathrm{H} 4$, and trimethylated $\mathrm{H} 3 \mathrm{~K} 4$, while non-EC lacked these marks [46]. The histone marks at the eNOS promoter can be regulated by the environment. Hypoxia, a classical cellular stress, causes a decrease in histone activating marks such as acetylation and H3K4 methylation under acute conditions and additionally histone eviction. Under chronic hypoxia, the histone octamers returned to normoxic levels, but the basal activating marks were not present [41]. It is also worth highlighting that hypoxia upregulates the expression of an antisense eNOS gene, sONE (eNOS antisense, NOS3AS) that overlaps the $3^{\prime}$ end of the eNOS gene [53]. sONE has been shown to regulate eNOS levels at the post-transcriptional level $[45,53,54]$.

Previous data have demonstrated that laminar flow induces eNOS expression through enhanced mRNA production, processing, and stability [55]. Recent studies have also identified various epigenetic processes that are responsive to flow. These epigenetic changes may play an active role in regulating eNOS expression. In response to laminar flow, there is increased acetylation of the histones $\mathrm{H} 3$ and $\mathrm{H} 4$ at the promoter, which is indicative of transcriptional activation [56]. Furthermore, HDACs can indirectly induce Krüppel-like factor 2 and eNOS transcription in laminar sheer stress [57]. Taken together, these data suggest that epigenetic mechanisms play a role in regulating eNOS expression in response to shear stress.

\section{RNA-Based Mechanisms}

The discovery of an extensive catalog of long RNA transcripts termed long non-coding RNAs (lncRNAs) that do not code for proteins provides a new perspective on the importance of RNA in gene regulation. IncRNAs encompass the third layer of epigenetic regulation. Although the field is in its infancy and the nuclear function of lncRNAs is the least understood epigenetic regulator, the discovery of IncRNAs has made us appreciate the other aspects of RNA function, mainly RNA transcription and secondary structure. IncRNAs can mediate activation or repression of target genes through DNA methylation and histone post-translational modifications, as described above [58]. IncRNAs are functionally distinct from small noncoding RNAs, namely microRNAs, which primarily mediate post-transcriptional repression in the cytoplasm. Interestingly, unlike protein-coding genes, lncRNAs lack a strong conservation across species, suggesting that they may be under rapid evolutionary divergence and key for speciation [58]. 
One of the earliest characterized lncRNAs is the X-inactive specific transcript (XIST), which is involved in female X-chromosome inactivation in mammals. This lncRNA works in conjunction with repressive histone marks and DNA methylation to silence one of the two X chromosomes in female somatic cells [59]. Initially, XIST and other IncRNAs were thought to be rare examples of this functional group of RNAs. A global and unbiased approach using chromatin state mapping identified unique signatures of $\mathrm{H} 3 \mathrm{~K} 4$ trimethylation at promoters and H3K36 trimethylation termed K4-K36 domains at actively transcribed genomic regions. This led to the identification of 1,600 human intergenic lncRNAs and has further expanded to more than 8,000 lncRNAs that may exist near or antisense to protein coding genes since 2007 $[58,60]$. Most early work has focused on the functional identification of lncRNAs and their interaction with other epigenetic modifying machineries, but the effects of the genomic context has become a prominent area of research $[58,61,62]$.

Two excellent examples that encompass all aspects of the lncRNA function come from the HOX gene clusters. HOTAIR is expressed from the HOXC cluster on chromosome 12 in humans and acts in trans to regulate the expression of developmental genes in the HOXD locus on chromosome 2. It silences the HOXD cluster, in part, by recruiting polycomb repressive complex 2 (PRC2), which facilitates the addition of H3K27 trimethylation marks. In general, this is a labile repressive histone mark. The mechanism for how this targeting occurs remains unclear [61]. A second IncRNA found in the HOX gene cluster is HOTTIP, which is expressed at the distal tip of the HOXA locus and promotes transcription, in cis, of the adjacent HOXA genes. It activates these genes, in part, through its interaction with the histone methyltransferase MLL, which mediates H3K4 trimethylation [62]. These two examples of IncRNAs provide good examples of IncRNAs with contrasting function, namely to act either in cis or trans to either activate or repress transcription, respectively. More complicated models exist where the IncRNA overlaps or are present within introns of coding genes. Two notable examples include sONE and ANRIL, which will be discussed below. In general, the study of lncRNAs is just beginning. Their roles must be distinguished functionally from the biological effects of the adjacent protein coding genes.

\section{Epigenetic Mediator: ANRIL}

GWAS have identified lncRNAs that may be relevant to the genetic predisposition to CVD, especially ischemic stroke and CAD. This concept is important, as it was not previously appreciated that lncRNAs were mechanistically important in CAD. An excellent example, and one we discuss in detail, is ANRIL. The lncRNA (ANRIL, CDKN2B antisense RNA) is found within the $I N K / A R F$ gene cluster. It was first identified by a germ line deletion in a melanoma-neural system tumor syndrome family in an unrelated discovery of the locus [63]. Only months afterward, the identification of several SNPs associated with a CAD risk were localized to a genomic region devoid of the protein-coding gene but in or near the ANRIL IncRNA [63-65]. One particular SNP (rs1333049) showed a modest effect size in heterozygotes, which was exaggerated in homozygotes $[\mathrm{OR}=1.47$ (95\% CI 1.27-1.70) and OR $=1.9(95 \% \mathrm{CI} 1.61-2.24)$, respectively; $\mathrm{p}=1.16 \times 10^{-13}$ ] [66]. Two other SNPs in the locus were identified, which exist in a cluster (rs10757274 and rs10757278). The former SNP is the strongest genetic predictor of early MI and is not associated with established CAD risk factors such as lipoproteins or hypertension, making ANRIL a key candidate [65]. The latter SNP showed a modest effect size in $\mathrm{MI}$ [OR $=1.26$ (95\% CI 1.16-1.36)] in heterozygotes and is exaggerated in homozygotes $[\mathrm{OR}=1.64(95 \% \mathrm{CI} 1.47-1.82)]$. In CAD, rs10757278 shows a modest effect size [OR $=1.29$ (95\% CI 1.21-1.38), $\mathrm{p}=3.6 \times 10^{-14}$ ] [64]. Moreover, this SNP was also identified in a GWAS study on atherosclerotic diseases, a major component of CAD [14].

The ANRIL genomic locus spans approximately $42 \mathrm{~kb}$ on the human chromosome 9p21. The molecular characterization of the encoded RNA has been complex due to the generation 
of multiple splice variants, both linear and circular [57]. Functional studies have found that ANRIL aids in cis recruitment of chromatin-modifying complexes, specifically polycomb repressive complex 1 and PRC2, to neighboring genes of the INK4b/ARF/INK4a locus. These protein-coding genes are known to serve as important regulators of cellular division and senescence [13]. ANRIL regulates these genes by recruiting PRC2 to add H3K27 trimethylation repressive methylation marks. H3K27 trimethylation is then recognized by PRC1, which establishes H2AK119 monoubiquitylation to silence transcription [67]. It is believed that ANRIL transcription, antisense to ARF/INK4b, and secondary RNA structure formation are able to interact and direct PRC1 and PRC2 to the adjacent INK4/ARF locus to mediate the establishment of these repressive marks [57]. The presence of these epigenetic marks is associated with chromatin compaction and transcriptional repression of these protein-coding genes $[35,67]$. One model suggests that the presence of the disease-associated SNP allele changes the abundance or function of ANRIL splice variants, resulting in their reduced ability to regulate the INK4/ARF locus. Alternatively, functionally important variability in linkage disequilibrium related to the disease-associated SNP may play a role in ANRIL function [57].

The clinical implications and the basic science discovery of lncRNAs are just emerging. ANRIL is a specific example of an IncRNA, which was identified through unbiased GWAS studies, and is associated with a non-Mendelian human disease and offers an exciting newer perspective on the CAD pathophysiology. Moreover, many unbiased GWAS studies have identified a significant proportion of hits that fall into genomic regions with no protein-coding genes termed 'gene deserts' [68]. This raises a key concept, namely that a gene can be implicated in the genetic cause of disease because it produces a functional RNA as an epigenetic modifier.

\section{Future Directions}

The use of epigenetic modifiers in the clinic has shown promise. DNMT inhibitors have been approved for myelodysplastic syndrome and acute myelogenous leukemia, while various HDAC inhibitors are being used for certain T-cell lymphomas [39]. Further use of epigenetic modifiers is bound to increase as our knowledge of epigenetics expands. Alternatively, epigenetic modifiers can also be used for prognostic purposes. For example, HOTAIR expression was found to be correlated with breast cancer metastasis and death, indicating that lncRNAs may have a prognostic purpose and potentially serve as a target in the future [58]. Importantly, there is research suggesting that HDAC inhibition may be of clinical use for CAD [39]. It would not be surprising if these findings may be further implicated in endothelial dysfunction and allow us to modulate important players in disease such as eNOS and ANRIL in diseased vasculature.

As noted by the famed physician William Osler in 1892, 'Longevity is a vascular question, and has been well expressed in the axiom that "a man is only as old as his arteries" ' [69]. As life expectancy increases, scientists must use new paradigms to help understand disease progression, especially in vascular diseases such as CAD. New therapies and approaches for CVD in general and CAD specifically are urgently needed to help decrease the tremendous socioeconomic burden caused by this spectrum of diseases. Limitations, specifically the cis/ trans paradigm, have arisen with classical models of transcription in vascular ECs. It is well established that our environment has chronic effects on gene expression in ECs. Epigenetic regulation in vascular ECs has provided a molecular basis for understanding the environmental impacts on the genome and disease susceptibility [3]. Most importantly, the dynamic nature of epigenetic modification in ECs offers the possibility of therapeutic intervention for non-Mendelian diseases such as CAD. 
Turgeon et al.: Epigenetics of Cardiovascular Disease: A New 'Beat' in Coronary Artery Disease

\section{Acknowledgments}

P.A.M. holds the Elisabeth Hofmann Chair in Translational Medicine at the University of Toronto and is supported by operating grants from CIHR MOP 79475 and NIH/HHLBI P01 HL076540-06A1. P.J.T. and A.N.S. gratefully acknowledge support from Queen Elizabeth II/ Heart and Stroke Foundation of Ontario Scholarship in Science and Technology scholarship.

\section{Disclosure Statement}

The authors have no conflicts of interest to declare.

\section{References}

1 Go AS, Mozaffarian D, Roger VL, Benjamin EJ, Berry JD, Borden WB, Bravata DM, Dai S, Ford ES, Fox CS, Franco S, Fullerton HJ, Gillespie C, Hailpern SM, Heit JA, Howard VJ, Huffman MD, Kissela BM, Kittner SJ, Lackland DT, Lichtman JH, Lisabeth LD, Magid D, Marcus GM, Marelli A, Matchar DB, McGuire DK, Mohler ER, Moy CS, Mussolino ME, Nichol G, Paynter NP, Schreiner PJ, Sorlie PD, Stein J, Turan TN, Virani SS, Wong ND, Woo D, Turner MB: Executive summary: heart disease and stroke statistics - 2013 update: a report from the American Heart Association. Circulation 2013;127:143-152.

- 2 Hansson GK: Inflammation, atherosclerosis, and coronary artery disease. N Engl J Med 2005;352:1685-1695.

3 Matouk CC, Turgeon PJ, Marsden PA: Epigenetics and stroke risk - beyond the static DNA code. Adv Genomics Genet 2012;2012:67-84.

4 Esper RJ, Nordaby RA, Vilarino JO, Paragano A, Cacharron JL, Machado RA: Endothelial dysfunction: a comprehensive appraisal. Cardiovasc Diabetol 2006;5:4.

- 5 Won D, Zhu SN, Chen M, Teichert AM, Fish JE, Matouk CC, Bonert M, Ojha M, Marsden PA, Cybulsky MI: Relative reduction of endothelial nitric-oxide synthase expression and transcription in atherosclerosis-prone regions of the mouse aorta and in an in vitro model of disturbed flow. Am J Pathol 2007;171:1691-1704.

- 6 Eshtehardi P, McDaniel MC, Suo J, Dhawan SS, Timmins LH, Binongo JN, Golub LJ, Corban MT, Finn AV, Oshinski JN, Quyyumi AA, Giddens DP, Samady H: Association of coronary wall shear stress with atherosclerotic plaque burden, composition, and distribution in patients with coronary artery disease. J Am Heart Assoc 2012; 1:e002543.

7 Marenberg ME, Risch N, Berkman LF, Floderus B, de Faire U: Genetic susceptibility to death from coronary heart disease in a study of twins. N Engl J Med 1994;330:1041-1046.

8 Peden JF, Farrall M: Thirty-five common variants for coronary artery disease: the fruits of much collaborative labour. Hum Mol Genet 2011;20(R2):R198-R205.

9 Fraga MF, Ballestar E, Paz MF, Ropero S, Setien F, Ballestar ML, Heine-Suner D, Cigudosa JC, Urioste M, Benitez J, Boix-Chornet M, Sanchez-Aguilera A, Ling C, Carlsson E, Poulsen P, Vaag A, Stephan Z, Spector TD, Wu YZ, Plass C, Esteller M: Epigenetic differences arise during the lifetime of monozygotic twins. Proc Natl Acad Sci USA 2005;102:10604-10609.

10 Wienke A, Holm NV, Skytthe A, Yashin AI: The heritability of mortality due to heart diseases: a correlated frailty model applied to Danish twins. Twin Res 2001;4:266-274.

-11 Manolio TA, Collins FS, Cox NJ, Goldstein DB, Hindorff LA, Hunter DJ, McCarthy MI, Ramos EM, Cardon LR, Chakravarti A, Cho JH, Guttmacher AE, Kong A, Kruglyak L, Mardis E, Rotimi CN, Slatkin M, Valle D, Whittemore AS, Boehnke M, Clark AG, Eichler EE, Gibson G, Haines JL, Mackay TF, McCarroll SA, Visscher PM: Finding the missing heritability of complex diseases. Nature 2009;461:747-753.

12 Holdt LM, Teupser D: Recent studies of the human chromosome 9p21 locus, which is associated with atherosclerosis in human populations. Arterioscler Thromb Vasc Biol 2012;32:196-206.

13 Congrains A, Kamide K, Ohishi M, Rakugi H: ANRIL: molecular mechanisms and implications in human health. Int J Mol Sci 2013;14:1278-1292.

14 Liu Y, Sanoff HK, Cho H, Burd CE, Torrice C, Mohlke KL, Ibrahim JG, Thomas NE, Sharpless NE: INK4/ARF transcript expression is associated with chromosome 9p21 variants linked to atherosclerosis. PLoS One 2009; 4:e5027.

15 Whitelaw NC, Whitelaw E: Transgenerational epigenetic inheritance in health and disease. Curr Opin Genet Dev 2008;18:273-279.

16 Heijmans BT, Tobi EW, Stein AD, Putter H, Blauw GJ, Susser ES, Slagboom PE, Lumey LH: Persistent epigenetic differences associated with prenatal exposure to famine in humans. Proc Natl Acad Sci USA 2008;105:1704617049. 
17 Painter RC, de Rooij SR, Bossuyt PM, Simmers TA, Osmond C, Barker DJ, Bleker OP, Roseboom TJ: Early onset of coronary artery disease after prenatal exposure to the Dutch famine. Am J Clin Nutr 2006;84:322-327; quiz 466-467.

18 Sumpio BE, Riley JT, Dardik A: Cells in focus: endothelial cell. Int J Biochem Cell Biol 2002;34:1508-1512.

19 Marsden PA, Brenner BM: Nitric oxide and endothelins: novel autocrine/paracrine regulators of the circulation. Semin Nephrol 1991;11:169-185.

20 Chiu JJ, Chien S: Effects of disturbed flow on vascular endothelium: pathophysiological basis and clinical perspectives. Physiol Rev 2011;91:327-387.

21 Chatzizisis YS, Coskun AU, Jonas M, Edelman ER, Feldman CL, Stone PH: Role of endothelial shear stress in the natural history of coronary atherosclerosis and vascular remodeling: molecular, cellular, and vascular behavior. J Am Coll Cardiol 2007;49:2379-2393.

-22 Papaioannou TG, Stefanadis C: Vascular wall shear stress: basic principles and methods. Hellenic J Cardiol 2005;46:9-15.

-23 Dai G, Kaazempur-Mofrad MR, Natarajan S, Zhang Y, Vaughn S, Blackman BR, Kamm RD, Garcia-Cardena G, Gimbrone MA Jr: Distinct end othelial phenotypes evoked by arterial waveforms derived from atherosclerosissusceptible and -resistant regions of human vasculature. Proc Natl Acad Sci USA 2004;101:14871-14876. Miranda TB, Jones PA: DNA methylation: the nuts and bolts of repression. J Cell Physiol 2007;213:384-390.

25 Hotchkiss RD: The quantitative separation of purines, pyrimidines, and nucleosides by paper chromatography. J Biol Chem 1948;175:315-332.

26 Scarano E, Iaccarino M, Grippo P, Parisi E: The heterogeneity of thymine methyl group origin in DNA pyrimidine isostichs of developing sea urchin embryos. Proc Natl Acad Sci USA 1967;57:1394-1400.

27 Law JA, Jacobsen SE: Establishing, maintaining and modifying DNA methylation patterns in plants and animals. Nat Rev Genet 2010;11:204-220.

28 Kagiwada S, Kurimoto K, Hirota T, Yamaji M, Saitou M: Replication-coupled passive DNA demethylation for the erasure of genome imprints in mice. EMBO J 2013;32:340-353.

29 Oswald J, Engemann S, Lane N, Mayer W, Olek A, Fundele R, Dean W, Reik W, Walter J: Active demethylation of the paternal genome in the mouse zygote. Curr Biol 2000;10:475-478.

-30 Tahiliani M, Koh KP, Shen Y, Pastor WA, Bandukwala H, Brudno Y, Agarwal S, Iyer LM, Liu DR, Aravind L, Rao A: Conversion of 5-methylcytosine to 5-hydroxymethylcytosine in mammalian DNA by MLL partner TET1. Science 2009;324:930-935.

-31 Ito S, Shen L, Dai Q, Wu SC, Collins LB, Swenberg JA, He C, Zhang Y: Tet proteins can convert 5-methylcytosine to 5-formylcytosine and 5-carboxylcytosine. Science 2011;333:1300-1303.

32 Bhutani N, Burns DM, Blau HM: DNA demethylation dynamics. Cell 2011;146:866-872.

-33 Yildirim O, Li R, Hung JH, Chen PB, Dong X, Ee LS, Weng Z, Rando OJ, Fazzio TG: Mbd3/NURD complex regulates expression of 5-hydroxymethylcytosine marked genes in embryonic stem cells. Cell 2011;147:1498-1510.

-34 Jeffery L, Nakielny S: Components of the DNA methylation system of chromatin control are RNA-binding proteins. J Biol Chem 2004;279:49479-49487.

-35 Wang GG, Allis CD, Chi P: Chromatin remodeling and cancer, part I: covalent histone modifications. Trends Mol Med 2007;13:363-372.

-36 Tan M, Luo H, Lee S, Jin F, Yang JS, Montellier E, Buchou T, Cheng Z, Rousseaux S, Rajagopal N, Lu Z, Ye Z, Zhu Q, Wysocka J, Ye Y, Khochbin S, Ren B, Zhao Y: Identification of 67 histone marks and histone lysine crotonylation as a new type of histone modification. Cell 2011;146:1016-1028.

37 Kouzarides T: Chromatin modifications and their function. Cell 2007;128:693-705.

38 Strahl BD, Allis CD: The language of covalent histone modifications. Nature 2000;403:41-45.

-39 McKinsey TA: Therapeutic potential for HDAC inhibitors in the heart. Annu Rev Pharmacol Toxicol 2012;52: 303-319.

40 Heintzman ND, Stuart RK, Hon G, Fu Y, Ching CW, Hawkins RD, Barrera LO, Van Calcar S, Qu C, Ching KA, Wang W, Weng Z, Green RD, Crawford GE, Ren B: Distinct and predictive chromatin signatures of transcriptional promoters and enhancers in the human genome. Nat Genet 2007;39:311-318.

-41 Fish JE, Yan MS, Matouk CC, St Bernard R, Ho JJ, Gavryushova A, Srivastava D, Marsden PA: Hypoxic repression of endothelial nitric-oxide synthase transcription is coupled with eviction of promoter histones. J Biol Chem 2010;285:810-826.

-42 Wilcox JN, Subramanian RR, Sundell CL, Tracey WR, Pollock JS, Harrison DG, Marsden PA: Expression of multiple isoforms of nitric oxide synthase in normal and atherosclerotic vessels. Arterioscler Thromb Vasc Biol 1997;17:2479-2488.

-43 Hajra L, Evans AI, Chen M, Hyduk SJ, Collins T, Cybulsky MI: The NF-kappa B signal transduction pathway in aortic endothelial cells is primed for activation in regions predisposed to atherosclerotic lesion formation. Proc Natl Acad Sci USA 2000; 97:9052-9057.

-44 Stauss HM, Godecke A, Mrowka R, Schrader J, Persson PB: Enhanced blood pressure variability in eNOS knockout mice. Hypertension 1999;33:1359-1363.

-45 Fish JE, Matouk CC, Yeboah E, Bevan SC, Khan M, Patil K, Ohh M, Marsden PA: Hypoxia-inducible expression of a natural cis-antisense transcript inhibits endothelial nitric-oxide synthase. J Biol Chem 2007;282:1565215666.

46 Fish JE, Matouk CC, Rachlis A, Lin S, Tai SC, D’Abreo C, Marsden PA: The expression of endothelial nitric-oxide synthase is controlled by a cell-specific histone code. J Biol Chem 2005;280:24824-24838. 
Turgeon et al.: Epigenetics of Cardiovascular Disease: A New 'Beat' in Coronary Artery Disease

47 Chan Y, Fish JE, D’Abreo C, Lin S, Robb GB, Teichert AM, Karantzoulis-Fegaras F, Keightley A, Steer BM, Marsden PA: The cell-specific expression of endothelial nitric-oxide synthase: a role for DNA methylation. J Biol Chem 2004;279:35087-35100.

-48 Marsden PA, Schappert KT, Chen HS, Flowers M, Sundell CL, Wilcox JN, Lamas S, Michel T: Molecular cloning and characterization of human endothelial nitric oxide synthase. FEBS Lett 1992;307:287-293.

49 Marsden PA, Heng HH, Scherer SW, Stewart RJ, Hall AV, Shi XM, Tsui LC, Schappert KT: Structure and chromosomal localization of the human constitutive endothelial nitric oxide synthase gene. J Biol Chem 1993;268: 17478-17488.

-50 Karantzoulis-Fegaras F, Antoniou H, Lai SL, Kulkarni G, D’Abreo C, Wong GK, Miller TL, Chan Y, Atkins J, Wang Y, Marsden PA: Characterization of the human endothelial nitric-oxide synthase promoter. J Biol Chem 1999; 274:3076-3093.

51 Teichert AM, Miller TL, Tai SC, Wang Y, Bei X, Robb GB, Phillips MJ, Marsden PA: In vivo expression profile of an endothelial nitric oxide synthase promoter-reporter transgene. Am J Physiol Heart Circ Physiol 2000; 278:H1352-H1361.

52 Shirodkar AV, St Bernard R, Gavryushova A, Kop A, Knight BJ, Yan MS, Man HS, Sud M, Hebbel RP, Oettgen P, Aird WC, Marsden PA: A mechanistic role for DNA methylation in endothelial cell (EC)-enriched gene expression: relationship with DNA replication timing. Blood 2013;121:3531-3540.

53 Robb GB, Carson AR, Tai SC, Fish JE, Singh S, Yamada T, Scherer SW, Nakabayashi K, Marsden PA: Post-transcriptional regulation of endothelial nitric-oxide synthase by an overlapping antisense mRNA transcript. J Biol Chem 2004;279:37982-37996.

54 Ho JJ, Robb GB, Tai SC, Turgeon PJ, Mawji IA, Man HS, Marsden PA: Active stabilization of human endothelial nitric oxide synthase mRNA by hnRNP E1 protects against antisense RNA and microRNAs. Mol Cell Biol 2013; 33:2029-2046.

-55 Weber M, Hagedorn CH, Harrison DG, Searles CD: Laminar shear stress and 3' polyadenylation of eNOS mRNA. Circ Res 2005;96:1161-1168.

56 Huddleson JP, Ahmad N, Srinivasan S, Lingrel JB: Induction of KLF2 by fluid shear stress requires a novel promoter element activated by a phosphatidylinositol 3-kinase-dependent chromatin-remodeling pathway. J Biol Chem 2005;280:23371-23379.

57 Burd CE, Jeck WR, Liu Y, Sanoff HK, Wang Z, Sharpless NE: Expression of linear and novel circular forms of an INK4/ARF-associated non-coding RNA correlates with atherosclerosis risk. PLoS Genet 2010;6:e1001233.

-58 Rinn JL, Chang HY: Genome regulation by long noncoding RNAs. Annu Rev Biochem 2012;81:145-166.

-59 Lee JT, Bartolomei MS: X-inactivation, imprinting, and long noncoding RNAs in health and disease. Cell 2013; 152:1308-1323.

60 Guttman M, Amit I, Garber M, French C, Lin MF, Feldser D, Huarte M, Zuk O, Carey BW, Cassady JP, Cabili MN, Jaenisch R, Mikkelsen TS, Jacks T, Hacohen N, Bernstein BE, Kellis M, Regev A, Rinn JL, Lander ES: Chromatin signature reveals over a thousand highly conserved large non-coding RNAs in mammals. Nature 2009;458: 223-227.

-61 Rinn JL, Kertesz M, Wang JK, Squazzo SL, Xu X, Brugmann SA, Goodnough LH, Helms JA, Farnham PJ, Segal E, Chang HY: Functional demarcation of active and silent chromatin domains in human HOX loci by noncoding RNAs. Cell 2007;129:1311-1323.

-62 Wang KC, Yang YW, Liu B, Sanyal A, Corces-Zimmerman R, Chen Y, Lajoie BR, Protacio A, Flynn RA, Gupta RA, Wysocka J, Lei M, Dekker J, Helms JA, Chang HY: A long noncoding RNA maintains active chromatin to coordinate homeotic gene expression. Nature 2011;472:120-124.

-63 Pasmant E, Laurendeau I, Heron D, Vidaud M, Vidaud D, Bieche I: Characterization of a germ-line deletion, including the entire INK4/ARF locus, in a melanoma-neural system tumor family: identification of ANRIL, an antisense noncoding RNA whose expression coclusters with ARF. Cancer Res 2007;67:3963-3969.

64 Helgadottir A, Thorleifsson G, Manolescu A, Gretarsdottir S, Blondal T, Jonasdottir A, Sigurdsson A, Baker A, Palsson A, Masson G, Gudbjartsson DF, Magnusson KP, Andersen K, Levey AI, Backman VM, Matthiasdottir S, Jonsdottir T, Palsson S, Einarsdottir H, Gunnarsdottir S, Gylfason A, Vaccarino V, Hooper WC, Reilly MP, Granger CB, Austin H, Rader DJ, Shah SH, Quyyumi AA, Gulcher JR, Thorgeirsson G, Thorsteinsdottir U, Kong A, Stefansson K: A common variant on chromosome 9p21 affects the risk of myocardial infarction. Science 2007;316:1491-1493.

65 McPherson R, Pertsemlidis A, Kavaslar N, Stewart A, Roberts R, Cox DR, Hinds DA, Pennacchio LA, TybjaergHansen A, Folsom AR, Boerwinkle E, Hobbs HH, Cohen JC: A common allele on chromosome 9 associated with coronary heart disease. Science 2007;316:1488-1491.

-66 Wellcome Trust Case Control Consortium: Genome-wide association study of 14,000 cases of seven common diseases and 3,000 shared controls. Nature 2007;447:661-678.

67 Yap KL, Li S, Munoz-Cabello AM, Raguz S, Zeng L, Mujtaba S, Gil J, Walsh MJ, Zhou MM: Molecular interplay of the noncoding RNA ANRIL and methylated histone $\mathrm{H} 3$ lysine 27 by polycomb CBX7 in transcriptional silencing of INK4a. Mol Cell 2010;38:662-674.

-68 Hindorff LA, Sethupathy P, Junkins HA, Ramos EM, Mehta JP, Collins FS, Manolio TA: Potential etiologic and functional implications of genome-wide association loci for human diseases and traits. Proc Natl Acad Sci USA 2009;106:9362-9367.

69 Osler W: The Principles and Practice of Medicine. New York, D. Appleton and Company, 1892. 